\title{
Insulin receptor substrate-1 in osteoblast is indispensable for maintaining bone turnover
}

\author{
Naoshi Ogata, ${ }^{1}$ Daichi Chikazu, ${ }^{1}$ Naoto Kubota, ${ }^{2}$ Yasuo Terauchi, ${ }^{2}$ \\ Kazuyuki Tobe, ${ }^{2}$ Yoshiaki Azuma, ${ }^{3}$ Tomohiro Ohta, ${ }^{3}$ Takashi Kadowaki, ${ }^{2}$ \\ Kozo Nakamura, ${ }^{1}$ and Hiroshi Kawaguchi ${ }^{1}$ \\ ${ }^{1}$ Department of Orthopaedic Surgery, and \\ ${ }^{2}$ Department of Metabolic Diseases, Graduate School of Medicine, University of Tokyo, Tokyo 113-8655, Japan \\ ${ }^{3}$ Teijin Co. Ltd., Tokyo 191-8512, Japan \\ Address correspondence to: Hiroshi Kawaguchi, Department of Orthopaedic Surgery, Faculty of Medicine, \\ University of Tokyo, Hongo 7-3-1, Bunkyo-ku, Tokyo 113-8655, Japan. \\ Phone: 81-33815-5411 ext. 33376; Fax: 81-33818-4082; E-mail: kawaguchi-ort@h.u-tokyo.ac.jp.
}

Received for publication November 30, 1999, and accepted in revised form February 14, 2000.

Insulin receptor substrates (IRS-1 and -2) are essential for intracellular signaling by insulin and IGFI, anabolic regulators of bone metabolism. Mice lacking the IRS-1 gene IRS-1//- showed severe osteopenia with low bone turnover. IRS-1 was expressed in osteoblasts, but not in osteoclasts, of wild-type (WT) mice. IRS-1/- osteoblasts treated with insulin or IGF-I failed to induce tyrosine phosphorylation of cellular proteins, and they showed reduced proliferation and differentiation. Osteoclastogenesis in the coculture of hemopoietic cells and osteoblasts depended on IRS-1 expression in osteoblasts and could not be rescued by IRS-1 expression in hemopoietic cells in the presence of not only IGF-I but also $1,25(\mathrm{OH})_{2} \mathrm{D}_{3}$. In addition, osteoclast differentiation factor (RANKL/ODF) was not induced by these factors in IRS-1/- osteoblasts. We conclude that IRS-1 deficiency in osteoblasts impairs osteoblast proliferation, differentiation, and support of osteoclastogenesis, resulting in lowturnover osteopenia. Osteoblastic IRS-1 is essential for maintaining bone turnover, because it mediates signaling by IGF-I and insulin and, we propose, also by other factors, such as $1,25(\mathrm{OH})_{2} \mathrm{D}_{3}$.

J. Clin. Invest. 105:935-943 (2000).

\section{Introduction}

Insulin and IGF-I induce a wide variety of growth and metabolic responses and play important roles in the anabolic regulation of bone metabolism (1-4). Patients with insulin deficiency as exemplified by insulin-dependent diabetes mellitus (IDDM) are reported to be associated with decreased bone mass: osteoporosis (5-7). Patients with Laron syndrome caused by IGF-I deficiency also exhibit osteoporosis (8). However, the cellular and molecular mechanism underlying the bone loss by the deficit of insulin and IGF-I signaling has not yet been clarified.

Insulin and IGF-I initiate cellular responses by binding to and activating their endogenous tyrosine kinase receptors $(9,10)$. The major substrates of both insulin and IGF-I receptor tyrosine kinases are known to be closely related high-molecular-weight proteins, insulin receptor substrate- 1 and -2 (IRS- 1 and -2 ), which become rapidly phosphorylated on multiple tyrosine residues after ligand stimulation (11). These phosphorylated substrates bind to proteins containing Src homology-2 domains, and these intermediate signals stimulate a variety of different downstream biological effects (11-13).

We and others generated mice lacking the IRS-1 gene (IRS-1/- mice) by homologous recombination $(14,15)$. Our previous report has shown that the growth of IRS$1^{-/-}$mice was retarded after 15.5 embryonic days and that the body weight was about $30 \%$ less than that of wild-type (WT) littermates at the age of 3,8 , and 15 weeks (14). In addition, IRS-1/-/ mice developed resistance to the glucose-lowering effects of insulin and IGFI. The serum level of insulin was higher whereas that of IGF-I was normal in IRS-1-/- mice (14). Except for these changes, IRS-1-1- mice exhibited normal appearance and no abnormalities in major organs such as brain, heart, liver, spleen, and kidney. The survival rate was identical between WT and IRS-1/- mice, and both male and female IRS-1-/- mice were fertile (14).

In this study, we found severe osteopenia in IRS-1/mice and investigated the cellular and molecular mechanism underlying the abnormality of bone metabolism using in vivo morphological analyses and ex vivo cell culture systems. Here we demonstrate the significant similarity between the pathophysiology of osteopenia in IRS-1/- mice and that in low-turnover osteoporosis in humans. IRS-1/- mice could be a new laboratory animal model for low-turnover osteoporosis and could give us a new clue to understanding the mechanism of bone turnover regulation.

\section{Methods}

Animals. Mice with the original C57BL6/CBA hybrid background were generated and maintained as reported previously (14). In each experiment, male and female 
homozygous WT and IRS-1/- mice that were littermates generated from the intercross between heterozygous mice were compared. In a preliminary experiment, we confirmed there was no difference of phenotype, including body weight and bone density, between the WT offspring mice generated from heterozygote intercrossings and native WT mice of the same genetic background. The genotype of the mice was determined by PCR. All mice were maintained according to the protocol approved by the Animal Care and Use Committee of the University of Tokyo.

Analysis of skeletal morphology. Bone radiographs of the excised femora and tibiae from 8-week-old WT and IRS$1^{-/-}$littermates were taken with a soft $\mathrm{x}$-ray apparatus (Type SRO-M50; Sofron, Tokyo, Japan). Three-dimensional CT scans were taken using a composite X-ray analyzing system (NX-HCP, NS-ELEX Inc., Tokyo, Japan). Bone mineral density (BMD) of bones from 4-, 8-, 12-, and 16-week-old mice was measured by single energy $\mathrm{x}-$ ray absorptiometry using a bone mineral analyzer (DCS-600R; Aloka Co., Tokyo, Japan). All histological analyses were carried out using 8-week-old WT and IRS$1^{-/-}$littermates. For Villanueva-Goldner staining, tibiae were excised, fixed with $100 \%$ ethanol, embedded in methyl methacrylate, and sectioned in $6-\mu \mathrm{m}$ slices. For double labeling, mice were injected subcutaneously with calcein ( $8 \mathrm{mg} / \mathrm{kg}$ body weight) at 10 days and 3 days before sacrifice. Tartrate-resistant acid phosphatase-positive (TRAP positive) cells were stained at $\mathrm{pH} 5.0$ in the presence of $\mathrm{L}(+)$-tartaric acid using naphthol AS-MX phosphate (Sigma Chemical Co., St. Louis, Missouri, USA) in $N, N$-dimethyl formamide as the substrate. The specimens were subjected to histomorphometric analyses under a light microscope with a micrometer, using an image analyzer (System Supply Co., Nagano, Japan). Parameters for the trabecular bone were measured in an area $1.2 \mathrm{~mm}$ in length from 0.1 $\mathrm{mm}$ below the growth plate at the proximal metaphysis of the tibiae. Parameters for the cortex bone were measured at the midshaft of the tibiae. The thickness of the growth plate was measured at the proximal tibiae.

Blood chemistries. Serum levels of insulin were measured by RIA kit (Shionogi Pharmacological Co., Osaka, Japan), and those of IGF-I and -II were measured by
ELISA kits (Fujisawa Pharmacological Co., Osaka, Japan) according the manufacturers' instructions.

Ex vivo osteoblast cultures. Osteoblasts were isolated from 6-8 calvariae of neonatal (3-5 days old) WT and $I R S-1^{-/-}$littermates generated from 3 pairs of heterozygous mice. Calvariae were digested for 10 minutes at $37^{\circ} \mathrm{C}$ in an enzyme solution containing $0.1 \%$ collagenase and $0.2 \%$ dispase in $\alpha$-modified MEM ( $\alpha$ MEM; GIBCO-BRL, Grand Island, New York, USA) 5 times. Cells isolated by the last 4 digestions were combined as an osteoblast population and cultured in $\alpha \mathrm{MEM}$ containing $10 \%$ FBS and $50 \mu \mathrm{g} / \mathrm{mL}$ ascorbic acid. For cell proliferation assay, primary osteoblasts were inoculated at a density of $10^{5}$ cells/well in a 24 -multiwell plate and cultured to confluency in the same medium for 2 days; serum was deprived for 12 hours before adding the experimental medium with or without IGF-I (10 nM), insulin (100 nM), or fibroblast growth factor-2 (FGF-2; $1 \mathrm{nM})$. Incorporation of $\left[{ }^{3} \mathrm{H}\right]$-thymidine $(1 \mu \mathrm{Ci} / \mathrm{mL}$ in the medium) added for the final 3 hours was measured at 24 hours of culture. For alkaline phosphatase (ALP) activity measurement, primary osteoblasts were inoculated at a density of $5 \times 10^{4}$ cells/well in a 24-multiwell plate and cultured in $\alpha$ MEM containing $10 \%$ FBS and $50 \mu \mathrm{g} / \mathrm{mL}$ ascorbic acid with or without IGF-I (10 nM), insulin $(100 \mathrm{nM})$, or bone morphogenetic protein-2 (BMP-2; $30 \mathrm{ng} / \mathrm{mL})$. At 14 days of culture, cells were washed with PBS and sonicated in $10 \mathrm{mM}$ Tris- $\mathrm{HCl}$ buffer ( $\mathrm{pH}$ 8.0) containing $1 \mathrm{mM} \mathrm{MgCl}_{2}$ and $0.5 \%$ Triton X-100. ALP activity in the lysate was measured by the hydrolysis of $p$-nitrophenyl phosphate to $p$-nitrophenol using a Wako ALP kit (Wako Pure Chemical Industry, Ltd., Osaka, Japan). The protein content was determined using BCA protein assay reagent (Pierce Chemical Co., Rockford, Illinois, USA).

Coculture of hemopoietic cells and osteoblasts. TRAP-positive multinucleated osteoclasts were generated from the hemopoietic cells derived from either WT or IRS-1//- littermates by coculturing them with osteoblasts derived from either WT or IRS-1/-. As a source of hemopoietic cells including osteoclast progenitors, we used bone marrow cells and spleen cells that were collected from 8 -week-old mice. Osteoblasts $\left(5 \times 10^{4}\right.$ cells/well $)$ isolated from neonatal mice as described above were cocul-

Table 1

Histomorphometry of trabecular and cortex bones of tibiae

\begin{tabular}{|c|c|c|c|c|c|c|c|c|c|c|}
\hline & \multicolumn{8}{|c|}{ Trabecular } & \multicolumn{2}{|c|}{ Cortex } \\
\hline & $\begin{array}{c}\mathrm{BV} / \mathrm{TV} \\
(\%)\end{array}$ & $\begin{array}{l}\text { Tb.Th } \\
(\mu \mathrm{m})\end{array}$ & $\begin{array}{c}\text { Ob.S/BS } \\
(\%)\end{array}$ & $\begin{array}{c}\mathrm{BFR} / \mathrm{BS} \\
\left(\mathrm{mm}^{3} / \mathrm{cm}^{2} / \text { year }\right)\end{array}$ & $\begin{array}{c}\text { OS/BS } \\
(\%)\end{array}$ & $\begin{array}{l}\text { Oc.N/B.Pm } \\
\text { (cells/10 cm) }\end{array}$ & $\begin{array}{c}\text { Oc.S/BS } \\
(\%)\end{array}$ & $\begin{array}{c}\text { ES/BS } \\
(\%)\end{array}$ & $\begin{array}{c}\text { OC.Th } \\
\left(\times 10^{-1} \mathrm{~mm}\right)\end{array}$ & $\begin{array}{c}\text { MAR } \\
(\mu \mathrm{m} / \text { day })\end{array}$ \\
\hline WT & $8.96 \pm 0.24$ & $30.44 \pm 1.98$ & $7.79 \pm 1.01$ & $5.49 \pm 0.89$ & $8.00 \pm 1.03$ & $120.89 \pm 11.22$ & $7.79 \pm 1.67$ & $9.47 \pm 1.28$ & $2.78 \pm 0.29$ & $2.16 \pm 0.34$ \\
\hline IRS-1-/- & $5.76 \pm 0.71^{\mathrm{A}}$ & $14.79 \pm 2.32^{\mathrm{A}}$ & $2.16 \pm 0.86^{\mathrm{A}}$ & $0.89 \pm 0.26^{A}$ & $1.23 \pm 0.18^{\mathrm{A}}$ & $59.46 \pm 12.53^{A}$ & $3.11 \pm 0.36^{\mathrm{A}}$ & $4.27 \pm 0.71^{\mathrm{A}}$ & $1.53 \pm 0.12^{\mathrm{A}}$ & N.D. \\
\hline
\end{tabular}


a

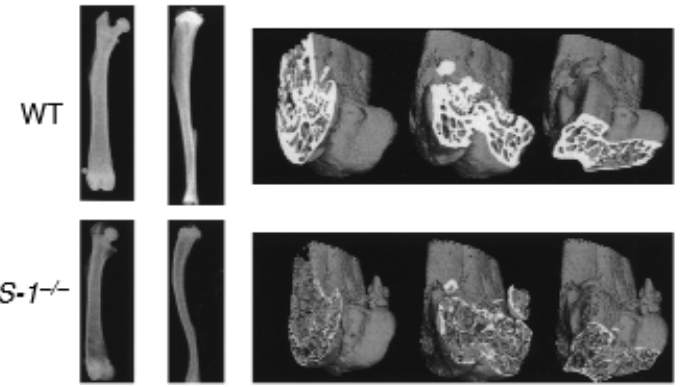

b
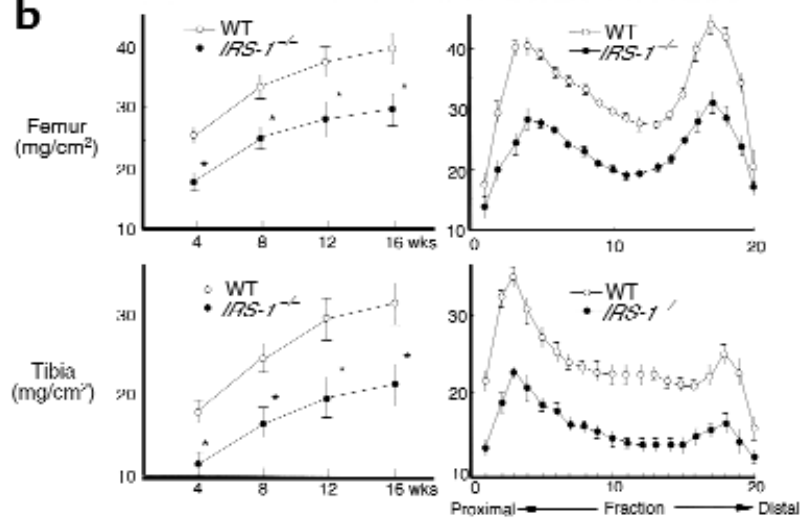

Figure 1

Radiological findings of the long bones of WT and IRS-1/- mice. (a) Plain x-ray images of femora (left) and tibiae (middle) and threedimensional CT images of distal femora (right) of representative 8 week-old WT and IRS-1-/- mice that are littermates generated from the intercross between heterozygous mice. (b) BMD of the femora and tibiae of WT and IRS-1/- littermates generated from 3 pairs of heterozygous mice. Left: BMD of the whole femora and tibiae at 4, 8, 12, and 16 weeks of age. Significantly different from WT mice, ${ }^{*} P<0.01$. Right: BMD of each of 20 equal longitudinal divisions of the femora and tibiae of 8-week-old mice. Data are expressed as mean (symbols) \pm SEM (error bars) for 8 bones/group for WT and IRS-1//- mice.

tured with bone marrow cells $\left(5 \times 10^{5}\right.$ cells/well $)$ or spleen cells $\left(10^{6}\right.$ cells/well $)$ in a 24 -multiwell plate in 0.5 $\mathrm{mL} /$ well of $\alpha \mathrm{MEM} / 10 \% \mathrm{FBS}$ for 8 days with or without $1,25(\mathrm{OH})_{2} \mathrm{D}_{3}(10 \mathrm{nM})$, IGF-I $(10 \mathrm{nM})$, prostaglandin $\mathrm{E}_{2}$ $\left(\mathrm{PGE}_{2} ; 100 \mathrm{nM}\right)$, parathyroid hormone (PTH; $\left.10 \mathrm{nM}\right)$, or IL-11(10 ng/mL). For the determination of osteoclastogenesis, cells were stained for TRAP as mentioned above. To determine the survival of osteoclasts, osteoclasts formed in 8 days of the coculture were collected by removing other cells by digesting with $0.001 \%$ pronase $\mathrm{E}$ and $0.02 \% \mathrm{EDTA}$ and cultured in $\alpha \mathrm{MEM} / 10 \%$ FBS for an additional 48 hours. At 4, 8, 12, $18,24,36$, and 48 hours, the number of TRAP-positive and trypan blue-negative multinucleated cells were counted, and the half-life was calculated from the survival curve. For the determination of bone resorption activity, osteoclasts were formed by the coculture for 8 days on $0.24 \%$ collagen gel coated on a 24 -multiwell plate. After cells were digested with $0.2 \%$ collagenase solution, a 1:50 aliquot including osteoclasts was seeded on a dentine slice and further cultured in $\alpha$ MEM containing $10 \%$ FBS for 48 hours. To compare the resorption activity of the osteoclasts of WT mice and that of IRS-1/- mice, the same number of TRAP-positive multinucleated cells were inoculated on a dentine slice and the total area of pits stained with $0.5 \%$ toluidine blue was evaluated using an image analyzer.

Immunoprecipitation and Western blot analysis. After stimulation by IGF-I $(10 \mathrm{nM})$ or insulin $(100 \mathrm{nM})$, cultured osteoblasts were washed twice with ice-cold PBS and lysed with TNE buffer $(10 \mathrm{mM}$ Tris- $\mathrm{HCl}, 150 \mathrm{mM} \mathrm{NaCl}$, 1\% NP-40, 1 mM EDTA, $10 \mathrm{mM} \mathrm{NaF}, 2 \mathrm{mM} \mathrm{Na}_{3} \mathrm{VO}_{4}, 1$ $\mathrm{mM}$ aminoethyl-benzenesulfonyl fluoride, and 10 $\mu \mathrm{g} / \mathrm{mL}$ aprotinin). The protein concentration in the cell lysate was measured using a Protein Assay Kit II (BIORAD, Hercules, California, USA). Immunoprecipitation was performed using antibodies either noncovalently bound or conjugated to protein G-Sepharose (GIBCOBRL). Equivalent amounts $(20 \mu \mathrm{g})$ of cell lysate were incubated with coupled antibody for 4 hours at $4{ }^{\circ} \mathrm{C}$, and the beads were washed 3 times with a lysis buffer and boiled in Laemmli sample buffer before electrophoresis. Each cell lysate or immunoprecipitated protein containing an equivalent amount of protein was electrophoresed by $8 \%$ SDS-PAGE and transferred to nitrocellulose membrane. To block nonspecific binding, membranes were incubated with $5 \%$ skim milk and then with polyclonal anti-mouse IRS-1 (Upstate Biotechnology Inc., Lake Placid, New York, USA) or nonimmune IgG. Immunoreactive bands were stained using the enhanced chemiluminescence (ECL) reaction (Amersham Life Sciences Inc., Arlington Heights, Illinois, USA) following the manufacturer's instructions.

Northern blotting and RT-PCR. For Northern blot analysis, cultured osteoblasts were incubated at a density of $10^{6}$ cells per dish in $100-\mathrm{mm}$ dishes and cultured in $\alpha \mathrm{MEM} / 10 \% \mathrm{FBS}$ with or without the resorptive factors above. Total RNA was extracted using an ISOGEN kit (Wako Pure Chemical). Ten micrograms of total RNA was electrophoresed in $1.2 \%$ agarose-formaldehyde gels and transferred onto nylon membrane filters (Hybond$\mathrm{N}$; Amersham International, Little Chalfont, United Kingdom). The membranes were hybridized for 2 hours at $65^{\circ} \mathrm{C}$ with cDNA probes for mouse osteoclast differentiation factor (RANKL/ODF), which was labeled using a multirandom primer oligonucleotide labeling kit (Boehringer, Mannheim, Germany) and [ $\left.{ }^{32} \mathrm{P}\right] \mathrm{dCTP}$ (Amersham International) according to the manufacturer's protocol. To investigate the expression of IRS-1 and - 2 in osteoblasts and osteoclastic cells, semiquantitative RT-PCR was performed within an exponential phase of the amplification. C7 cells kindly provided by S.I. Hayashi at Tottori University (Tottori, Japan) $(6 \times$ $10^{4}$ cells/dish) were cultured on $100-\mathrm{mm}$ dishes in aMEM containing $10 \% \mathrm{FBS}, 10 \mathrm{ng} / \mathrm{mL}$ of macrophage colony-stimulating factor (M-CSF; R\&D Systems Inc. Minneapolis, Minnesota, USA), and $30 \mathrm{ng} / \mathrm{mL}$ of soluble RANKL/ODF (PeproTech Inc., London, United Kingdom) for 6 days with a medium change at 3 days. Total RNA was extracted from cells cultured for 2, 4, and 6 days. Mature osteoclasts were prepared as 

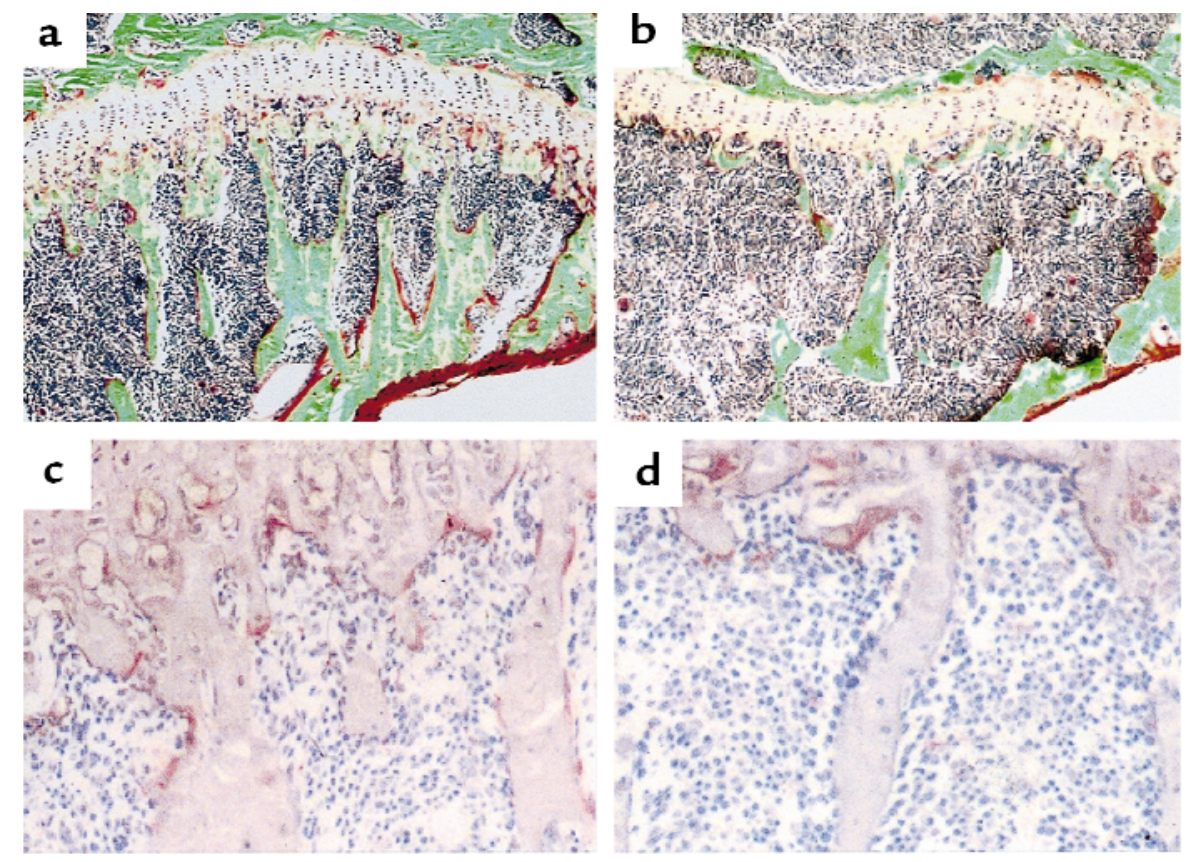

\section{Figure 2}

Histological features of the proximal metaphysis of 8-week-old WT and IRS-1-/- mice. In Villanueva-Goldner staining for representative WT (a) and IRS $-1^{-1-}$ (b) littermates (originally $\times 20$ ), mineralized bone is stained green and unmineralized osteoid is stained red. In TRAP staining for WT (c) and IRS-1 ${ }^{-1-}$ (d) littermates (originally $\times 100$ ), TRAP-positive osteoclasts are stained red. Histomorphometric parameters are shown in Table 1.

described above by the coculture of bone marrow cells $\left(2 \times 10^{7}\right.$ cells/dish $)$ and osteoblasts $\left(2 \times 10^{6}\right.$ cells/dish $)$ on $100-\mathrm{mm}$ culture dishes in $\alpha$ MEM containing $10 \%$ FBS and $1,25(\mathrm{OH})_{2} \mathrm{D}_{3}\left(10^{-8} \mathrm{M}\right)$ for 7 days with a medium change at 2 days. Total mRNA $(1 \mu \mathrm{g})$ was reverse transcribed using Super Script reverse transcriptase (Takara Shuzo Co., Ltd., Shiga, Japan) with random hexamer (Takara Shuzo), and 5\% of the reaction mixture was amplified with LA-Taq DNA polymerase (Takara Shuzo) using specific primer pairs:

5'-GCAGCCCCACCTGCCTCGAAAGGTAGACAC-3' and

5'-CAGCAATGCCTGTCCGCATGTCAGCATAGC-3' for IRS-1;

5'-GAAGACAGTGGGTACATGCGAATG-3' and

5'-CCTCATGGAGGAAGGCACTGCTG-3' for IRS-2;

$5^{\prime}$-CATGTAGGCCATGAGGTCCACCAC- $3^{\prime}$ and

5'-TGAAGGTCGGTGTGAACGGATTTGGC3' for G3PDH.

Up to 25 cycles of amplification were performed with a

Perkin Elmer PCR Thermal Cycler (PE-2400; PerkinElmer Corp., Norwalk, Connecticut, USA) at $94^{\circ} \mathrm{C}$ for 30 seconds, at $52-60^{\circ} \mathrm{C}$ for 60 seconds, and at $72^{\circ} \mathrm{C}$ for 90 seconds.

Statistical analysis. Means of groups were compared by ANOVA and significance of difference was determined by post hoc testing using Bonferroni's method.

\section{Results}

In vivo skeletal findings and blood chemistries. Because the lengths of femora and tibiae were about $20 \%$ shorter in IRS-1 $1^{-1-}$ than those of WT littermates at 8 weeks of age (Figure 1a), IRS-1 was suggested to be involved in the regulation of skeletal growth. Significant difference of the bone shape could not be detected between WT and
IRS-1 $1^{-/-}$mice. However, IRS-1 $1^{-/-}$mice showed severe osteopenia in these long bones by $\mathrm{x}$-ray and threedimensional computed tomographic (CT) analyses (Figure 1a). This finding was also observed in vertebral bodies (data not shown). BMD of these bones was decreased by more than $30 \%$ in IRS-1 $1^{-/}$mice at $4,8,12$, and 16 weeks of age compared with those in WT littermates (Figure 1b, left). To investigate the distribution of BMD of long bones at 8 weeks, the femora and tibiae were analyzed by dividing them longitudinally into 20 equal regions, and BMD of each fraction was measured (Figure 1b, right). BMD of each fraction was decreased to a similar extent in IRS-1/- mice, suggesting that both trabecular and cortex bones were equally affected. Histological analyses in the proximal tibiae of 8-week-old IRS-1/- mice revealed the decreases in trabecular bones, osteoid surface, and TRAP-positive osteoclasts (Figure 2). Histomorphometric measurements supported these histological observations (Table 1). Trabecular and cortex thickness was decreased by $51 \%$ and $45 \%$, respectively. Parameters for both bone formation (Ob.S/BS and BFR/BS) and resorption (Oc.N/B.Pm, Oc.S/BS, and ES/BS) were also significantly lower in IRS-1/- mice. The decrease in bone formation parameters (approximately $70-85 \%$ reduction) exceeded the decrease in bone resorption parameters (approximately 50-60\% reduction), indicating a state of low-turnover osteopenia that is a characteristic feature of senile osteoporosis in aged humans (16).

The thickness of the growth plate at the proximal tibiae was moderately decreased in IRS-1/- mice as compared with WT littermates $(60.7 \pm 4.8$ and $77.5 \pm 4.0 \mu \mathrm{m}$, 
mean \pm SEM of 7 mice each, respectively). Although chondrocytes of various differentiation stages were arranged regularly in a cartilaginous column, the number of columns and that of chondrocytes per column were decreased by approximately $20 \%$ and $30 \%$, respectively, in the IRS-1-/- growth plate cartilage. Because growth plate chondrocytes express IGF-I receptors and are responsive to IGF-I (17), these abnormalities may be due to the lack of action of IGF-I in IRS-1/- mice.

The serum insulin level was significantly higher in IRS-1-/- mice than in WT littermates both before (0.48 \pm 0.06 vs. $0.25 \pm 0.03 \mathrm{ng} / \mathrm{mL}$, mean \pm SEM of 5 mice each) and after $(0.52 \pm 0.06$ vs. $0.31 \pm 0.04 \mathrm{ng} / \mathrm{mL})$ glucose load at 8 weeks of age as reported previously (14). Serum IGF-I and IGF-II levels were similar between IRS-1/- and WT littermates $(129.07 \pm 7.37$ vs. $131.89 \pm 12.62 \mathrm{ng} / \mathrm{mL}$ and $9.60 \pm 0.46$ vs. $9.22 \pm 1.16 \mathrm{ng} / \mathrm{mL}$, respectively) at 8 weeks of age. The serum IGF-I level did not change significantly over the age of 8-16 weeks in either type of mice. No sex differences were apparent for any of these in vivo skeletal findings and blood chemistries.

Expression and signal transduction of IRS-1 in bone cells. Because IRS- 1 and -2 were reported to be differentially expressed in the variety of cells and tissues having different biological roles (18-22), we investigated the expressions of IRS- 1 and -2 in cells of osteoblastic and osteoclastic lineages by RT-PCR. Both substrates were expressed in WT osteoblasts from neonatal calvariae, whereas only IRS-2 was detected in IRS-1/-/ osteoblasts (Figure 3a). Immunoblotting using an anti-IRS-1 antibody showed that IRS-1 protein was expressed in WT osteoblasts (Figure 3b, lanes 7-9), but not in IRS-1/osteoblasts (lanes 10-12). Moreover, immunoblotting experiments using an anti-phosphotyrosine antibody of total cellular extracts (lanes 1-3) or immunoprecipitates with an anti-IRS-1 antibody (lanes 13-15) revealed that IGF-I and insulin induced tyrosine phosphorylation of cellular proteins including IRS-1 (arrowhead) in WT osteoblasts. However, in IRS-1 $1^{-/-}$osteoblasts neither phosphorylation of cellular proteins (lanes 4-6) nor IRS-1 (lanes 16-18) induced by IGF-I or insulin was observed, indicating that IRS- 1 is essential for signal transduction of IGF-I and insulin in osteoblasts.

On the contrary, IRS-1 expression was not detected in mature osteoclasts formed and isolated from cocultured marrow cells and osteoblasts not only from IRS-

a

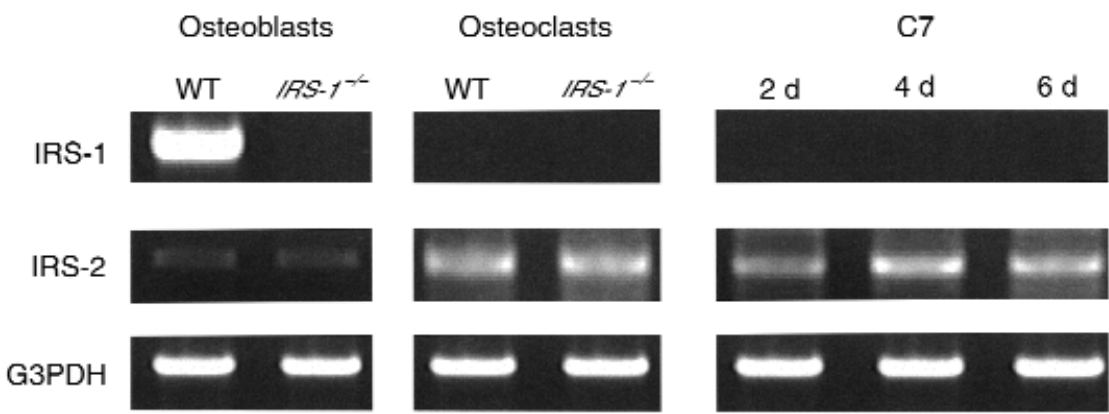

b



\section{Figure 3}

The expression of IRS-1 and -2 and the phosphorylation of cellular proteins in cell cultures. (a) Messenger RNA expression patterns of IRS1 and IRS-2 in osteoblasts and osteoclasts from WT and IRS-1-/- littermates and mouse osteoclast progenitor C7 cells at various differentiation stages were determined by semiquantitative RT-PCR within an exponential phase of the amplification. Total RNA was extracted from cultured osteoblasts from neonatal calvariae, osteoclasts formed in the coculture of marrow cells and osteoblasts, and C7 cells cultured for 2,4 , and 6 days in the presence of RANKL/ODF and M-CSF. IRS-1 expression was seen only in osteoblasts but not in cells of osteoclastic lineage, even when the amount of template cDNA or the number of amplification cycles was increased. (b) Induction of tyrosine phosphorylation of cellular proteins and IRS- 1 in osteoblasts from WT and IRS-1/- mice by IGF-I and insulin. Osteoblasts from neonatal calvariae of WT (lanes 1-3, 7-9, 13-15) and IRS-1-/- (lanes 4-6, 10-12, 16-18) littermates were treated with vehicle (lanes 1, 4, 7, 10, 13, and 16), IGFI (lanes 2, 5, 8, 11, 14, and 17) or insulin (lanes 3, 6, 9, 12, 15, and 18) for 2 minutes, and extracted cellular proteins were subjected to SDSPAGE. Lanes 1-6: immunoblotting with an anti-phosphotyrosine antibody; lanes 7-12: immunoblotting with an anti-IRS-1 antibody; lanes 13-18: immunoblotting with an anti-IRS-1 antibody for the osteoblast extracts immunoprecipitated with an anti-phosphotyrosine antibody. Arrowheads indicate $185-\mathrm{kD}$ protein (IRS-1). 


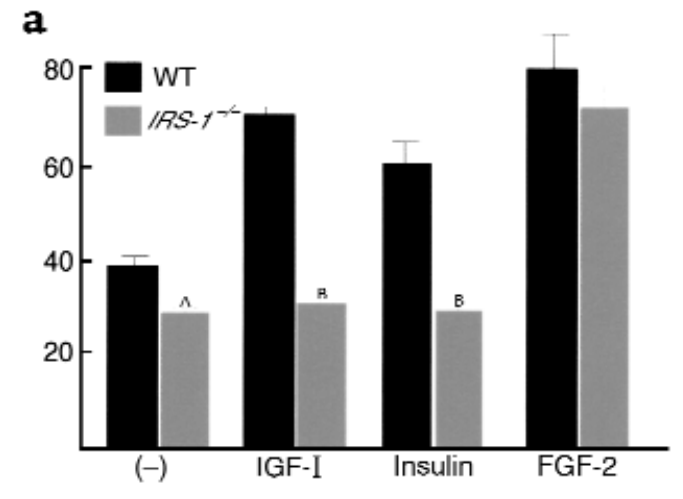

b

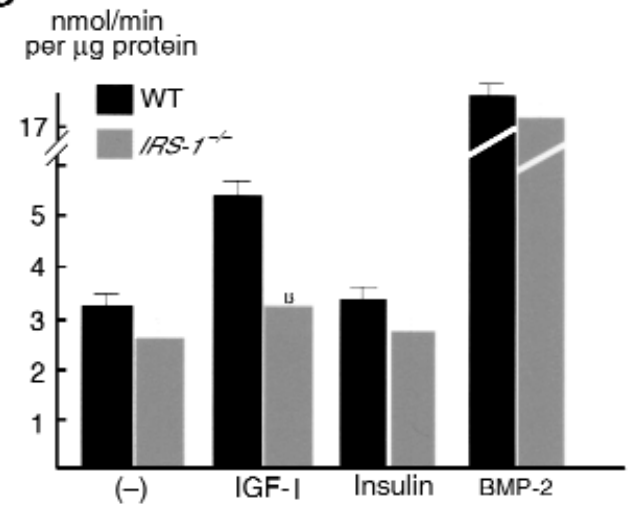

Figure 4

Cultures of osteoblasts from WT and IRS-1//- mice. (a) Cell proliferation of cultured osteoblasts. Osteoblasts from neonatal calvariae of WT and IRS-1/- littermates were cultured with or without IGF-I (10 $\mathrm{nM})$, insulin (100 nM), or FGF-2 (1 nM) for 24 hours, and the cell proliferation was determined by $\left[{ }^{3} \mathrm{H}\right]-\mathrm{TdR}$ incorporation into DNA. (b) ALP activity of osteoblasts from WT or IRS-1//- neonatal calvariae cultured with or without IGF-I (10 nM), insulin (100 nM), or BMP-2 $(30 \mathrm{ng} / \mathrm{mL})$ at 14 days of culture. Data are expressed as mean (bars) \pm SEM (error bars) for 8 wells/group. Significantly different from WT cultures, ${ }^{A} P<0.05,{ }^{B} P<0.01$.

$1^{-/-}$mice but also from WT mice (Figure 3a). Because osteoclast precursor cells are difficult to isolate in high purity, we used immortal mouse macrophage cell line C7 cells, which are known to differentiate into osteoclasts after 5-6 days of culture in the presence of soluble RANKL/ODF and M-CSF $(23,24)$. IRS- 1 expression also could not be detected in C7 cells cultured for 2, 4, and 6 days, including various differentiation stages of osteoclastic cells. In contrast, IRS-2 was abundantly expressed in isolated mature osteoclasts and C7 cells of various differentiation stages.

Analyses of cultured osteoblasts and osteoclasts. To learn the cellular mechanism underlying the abnormalities in the bone of IRS-1/- mice, cultured osteoblasts and osteoclasts were examined. Cultured osteoblasts from IRS-1/-- mice showed significantly reduced proliferation determined by $\left[{ }^{3} \mathrm{H}\right]-\mathrm{TdR}$ uptake as compared with WT osteoblasts (Figure 4a) in the control culture. In osteoblasts from WT mice, IGF-I stimulated not only cell proliferation but also cell differentiation deter- mined by ALP activity (Figure 4, a and b) and insulinstimulated proliferation (Figure 4a). There was no stimulation of proliferation or differentiation by IGFI or insulin in IRS-1-1- osteoblast cultures. On the other hand, the stimulation of cell proliferation by FGF-2 and the stimulation of cell differentiation by BMP-2 was similar in both WT and IRS-1 $1^{-/-}$osteoblasts, indicating that impaired proliferation and differentiation in cultured osteoblasts from IRS-1/- mice were specific to IGF-I and insulin.

Osteoclasts are known to be derived from hemopoietic cells and to require the cell-cell interaction with osteoblasts/stromal cells for differentiation (25). To investigate osteoclast formation, we measured the number of TRAP-positive multinucleated osteoclasts formed in the coculture system of bone marrow cells and primary osteoblasts. Osteoclastogenesis in the coculture induced not only by IGF-I but also by $1,25(\mathrm{OH})_{2} \mathrm{D}_{3}$ or their combination was decreased when both cells were derived from IRS-1//- mice as compared with when both cells were derived from WT mice (Figure 5a). Other conventional bone resorptive factors, PGE 2 , PTH, and IL-11, also induced osteoclastogenesis in the coculture; however, this stimulation was not distinguishable between the cultures of WT:WT and IRS-1-I:IRS-1-/- cells. These results were reproducible when spleen cells were used instead of bone marrow cells as a source of hemopoietic cells (data not shown). Recently, the TNF family molecule RANKL/ODF (also known as TRANCE and OPGL) was identified as a key membrane-associated molecule expressed on osteoblasts/stromal cells inducing osteoclastogenesis $(24,26)$. Hence, we examined the regulation of RANKL/ODF expression in osteoblasts from WT and $I R S-1^{-/-}$mice by these resorptive factors. The regulation of RANKL/ODF expression and of osteoclastogenesis by these factors showed good correlation: RANKL/ODF induction by $1,25(\mathrm{OH})_{2} \mathrm{D}_{3}$ and/or IGF-I was decreased in IRS-1/- osteoblasts as compared with WT osteoblasts, whereas the induction by $\mathrm{PGE}_{2}$, PTH, and IL-11 was identical in WT and IRS-1/- osteoblasts (Figure 5a).

In the presence of $1,25(\mathrm{OH})_{2} \mathrm{D}_{3}$, impaired osteoclastogenesis in the coculture of IRS-1/- cells was restored by replacing osteoblasts with WT osteoblasts, but not by replacing marrow cells with WT marrow cells (Figure 5b, top). This result was also reproducible when spleen cells were used as a source of hemopoietic cells (data not shown). When osteoclasts formed in the coculture were isolated and further cultured on a dentine slice for two days, the area of resorption pits correlated with the number of osteoclasts formed (Figure 5b, bottom). In addition, individual osteoclasts from IRS-1/- mice formed resorption pits approximately equal in area to those formed by WT mice. When the same number of osteoclasts were seeded, the total pit area resorbed by IRS-1/osteoclasts was $108.2 \pm 9.7 \%$ (mean \pm SEM) of that resorbed by WT osteoclasts. Survival curves showed no difference between the half-lives of WT and IRS-1 ${ }^{-/-}$ 
a.
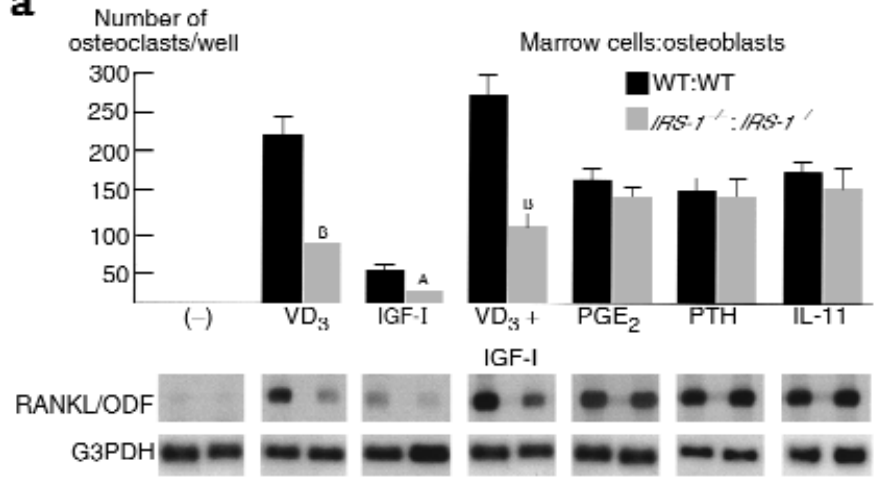

b

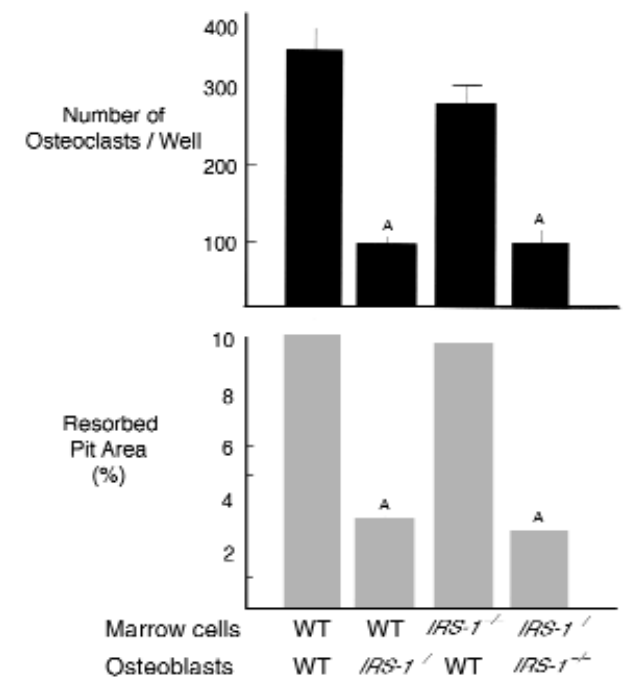

Figure 5

Osteoclastogenesis in the coculture of bone marrow cells and osteoblasts. (a) The number of TRAP-positive multinucleated osteoclasts formed in the coculture of marrow cells and osteoblasts both from WT or IRS-1-/- littermates for 8 days in the presence or absence of $1,25(\mathrm{OH})_{2} \mathrm{D}_{3}\left(\mathrm{VD}_{3}\right.$, $10 \mathrm{nM})$, IGF-I (10 nM), PGE 2 (100 nM), PTH (10 $\mathrm{nM})$, and IL-11 $(10 \mathrm{ng} / \mathrm{mL})$ was counted. Data are expressed as mean (bars) \pm SEM (error bars) for 8 wells/group. Significantly different from WT cultures, ${ }^{A} P<0.05,{ }^{B} P<0.01$. Steady-state mRNA levels of RANKL/ODF in cultured osteoblasts from neonatal WT and IRS-1-l- littermates were determined by Northern blot analysis after 24 hours of culture with or without the factors above. (b) The number of osteoclasts formed in the coculture of marrow cells and osteoblasts from WT and IRS-1-/- littermates in the presence of $1,25(\mathrm{OH})_{2} \mathrm{D}_{3}(10 \mathrm{nM})$ (top) and the pit area resorbed by osteoclasts for an additional 48 hours of coculture on a dentine slice (bottom). Data are expressed as mean (bars) \pm SEM (error bars) for 12 wells/group. Significantly different from WT:WT culture, ${ }^{A} P<0.01$. osteoclasts (12.1 hours and 12.9 hours, respectively). These results strongly suggest that the decrease in bone resorption in $I R S-1^{-/-}$mice is caused by a defect in osteoblasts to support osteoclast differentiation, but is not due to intrinsic abnormalities of osteoclast progenitors or reduced activity/survival of mature osteoclasts.

\section{Discussion}

We have shown in this study by radiological and histological analyses of bone phenotypes of $I R S-1^{-/-}$mice that IRS- 1 is essential to maintain bone mass and bone turnover. As a mechanism of this abnormality of IRS$1^{-/-}$bones, ex vivo cell culture experiments showed that the stimulatory effects of IGF-I and insulin on proliferation and differentiation seen in WT osteoblasts that abundantly express IRS-1 were abrogated in IRS-1-/osteoblasts. Moreover, the differentiation of osteoclasts that do not express IRS-1 was also decreased in IRS-1/mice owing to the impairment of the ability of osteoblasts to support osteoclastogenesis.

Because signal transduction by IGF-I and insulin was markedly diminished in IRS-1/- osteoblasts, the severe osteopenia in IRS-1/- mice may largely be due to the loss of IGF-I and insulin signaling. IGF-I is a potent autocrine/paracrine factor for osteoblast proliferation and differentiation $(3,4)$. Actions of other anabolic agents such as PTH and prostaglandin on bone forma- tion are also reported to be mediated by IGF-I production by osteoblasts (27-29). A relationship between BMD and IGF-I is suggested by a study showing a correlation of serum and skeletal IGF-I levels with BMD between 2 healthy inbred strains of mice (30). In humans, accumulating evidence has suggested a positive correlation between the serum IGF-I level and BMD in postmenopausal women $(31,32)$. The anabolic effect of insulin on bone formation may be related to its ability to stimulate cell proliferation $(1,2)$. Streptozotocininduced diabetic animals with impaired pancreatic insulin production lose bone rapidly, and this loss is offset by insulin replacement (33). Insulin deficiency as exemplified by IDDM patients is also associated with decreased bone mass (5-7). However, the change of bone mass in non-insulin-dependent diabetes mellitus (NIDDM) patients is controversial (5-7, 34-36). Although previous reports demonstrated a decrease in bone mass in NIDDM patients $(5,35)$, accumulating evidence has shown that obese NIDDM patients have normal or even increased bone mass $(6,7,34,36)$. This might be due to the increased physical stress on the skeleton or to hyperinsulinemia in NIDDM as a result of the osteoanabolic effect of insulin. Whether or not the response of bone cells to insulin is affected in NIDDM patients similarly to those of cells regulating glucose metabolism such as muscle, liver, and adipose 
tissues is a point to be elucidated. Although the IRS-1-/mouse is considered to be a model resembling NIDDM patients with hyperinsulinemia/insulin resistance in whom IRS-1 function might be impaired (37), this model is unlikely to define mechanisms of abnormalities of bone metabolism in these patients. The IRS-1/mouse may serve as a model of low-turnover osteopenia associated with insulin and IGF-I resistance.

The decrease in IRS-1-/- osteoblast proliferation was seen not only in the stimulated culture by IGF-I or insulin but also in the control culture, although not as strongly in the latter (Figure 4a). This possibly may be due to the blockage of signaling of endogenous IGF-I acting as an autocrine/paracrine factor in the culture. The concentrations of IGF-I in the culture medium were $0.52 \pm 0.10$ and $0.49 \pm 0.09 \mathrm{nM}($ mean \pm SEM) in the control WT and IRS-1/- cultures, respectively. In addition, serum IGF-I levels were similar between WT and IRS-1/- mice over the age of 8-16 weeks, suggesting the absence of systemic compensation for impaired IGF-I bioactivity. Hence, the decreased bone formation in vivo in $I R S-1^{-/}$mice is likely to be due to the deficit of anabolic signaling of endogenous IGF-I produced by osteoblasts acting as an autocrine/paracrine factor. IGF-I may also mediate the effects of other anabolic factors (27-29), but stimulation of osteoblast proliferation by FGF-2 and stimulation of differentiation by BMP-2 were not reduced in IRS-1/- osteoblast cultures, indicating that the anabolic effects of these factors are not mediated by IGF-I/IRS-1.

The decrease in $1,25(\mathrm{OH})_{2} \mathrm{D}_{3}$ - or IGF-I-stimulated osteoclast formation from IRS-1/- hemopoietic cells showed good correspondence with decreased RANKL/ODF mRNA expression in IRS-1-/- osteoblasts and was reversed by WT osteoblasts. In addition, there was no reduction in IRS-1/- osteoclast activity or survival. We conclude, therefore, that the decrease in osteoclastogenesis in IRS-1/- mice was caused by the decreased ability of IRS-1/-/- osteoblasts to support osteoclast differentiation. The impairment of RANKL/ODF induction in IRS-1//- osteoblasts stimulated by $1,25(\mathrm{OH})_{2} \mathrm{D}_{3}$ suggests some cross-talk mechanism between the signaling pathways of IRS- 1 and $1,25(\mathrm{OH})_{2} \mathrm{D}_{3}$. The fact that mRNA and protein levels of vitamin $\mathrm{D}$ receptor (VDR) determined by RT-PCR and Western blotting, respectively, were identical between WT and IRS-1/- osteoblasts (data not shown) suggests the convergence of these signaling pathways after $1,25(\mathrm{OH})_{2} \mathrm{D}_{3}$ binds to VDR. Because the main signaling pathways downstream of IRS- 1 are known to be those of mitogen-activated protein (MAP) kinase and phosphatidylinositol 3 (PI3) kinase (11), it is possible that either pathway may be connected with the VDR signaling. In fact, several cross-talk mechanisms of signal transduction pathways between MAP kinase and nuclear receptors have been identified recently (38). Estrogen receptor, another nuclear receptor that is essential to regulate osteoblast function, is known to be activated through phosphorylation by MAP kinase (39-41). Regarding VDR, its heterodimer partner, RXR, has been reported to be phosphorylated by MAP kinase activation; however, the phosphorylation of RXR is inhibitory on $1,25(\mathrm{OH})_{2} \mathrm{D}_{3}$ signal transduction (42). Hence, the signaling pathways of VDR and IRS- 1 might rather converge on some molecules in PI3 kinase pathways. Although these cross-talk mechanisms have not been investigated in osteoblasts, further studies will elucidate the detailed mechanisms of cross-talk of membrane and nuclearreceptor signaling such as IRS- 1 and VDR.

Despite the fact that both IRS- 1 and -2 are ubiquitously expressed, these expression patterns are different among cells and tissues (18-22). Most hemopoietic cells express IRS-2 but not IRS-1 (21), and cells of osteoclastic lineage showed an identical expression pattern in this study. IGF-I is known to stimulate osteoclastic bone resorption not only through indirect action but also through direct action on osteoclast progenitors or mature osteoclasts (43-46). The receptor for insulin has also been identified on mature osteoclasts and regulates osteoclast function (47). Osteoclastogenesis from osteoclast progenitors was impaired but not abrogated by IRS-1 deficiency, and the activity and survival of mature osteoclasts were not affected. Hence, IRS-2 may play an important role in the direct action of IGF-I and insulin on osteoclastic cells and contribute to the regulation of bone turnover in a different way from IRS-1. This question is currently being addressed in our laboratory.

From this study, it is concluded that IRS-1 deficiency in osteoblasts impairs osteoblast proliferation and differentiation, as well as support of osteoclastogenesis, resulting in low-turnover osteopenia. We therefore propose that osteoblastic IRS-1 plays a critical role in maintaining bone turnover, not only because it is essential for IGF-I and insulin signaling, but also because it may be involved in signal transduction for other factors such as $1,25(\mathrm{OH})_{2} \mathrm{D}_{3}$. Further clinical studies will reveal the contribution of IRS-1 to the pathophysiology of several bone disorders such as osteoporosis.

\section{Acknowledgments}

We thank K. Hoshi, I. Nakamura, C.C. Pilbeam, and L.G. Raisz for suggestions and critical review, and the hard tissue research team at Kureha Chemical Co., Ltd. for technical assistance. This work was supported by a Grant-in-Aid for Scientific Research from the Japanese Ministry of Education, Science, Sports and Culture (11470301), a Grant-in-Aid for Creative Basic Research (10NP0201) from the Ministry of Education, Science, Sports, and Culture, the Japan Orthopaedics and Traumatology Foundation (0103), a Bristol-Myers Squibb/ Zimmer Unrestricted Research Grant, and the Uehara Memorial Foundation.

\footnotetext{
1. Thomas, D.M., Hards, D.K., Rogers, S.D., Ng, K.W., and Best, J.D. 1997. Insulin and bone, clinical and scientific view. Endocrinol. Metab. North. Am. 4:5-17.

2. Thomas, D.M., Hards, D.K., Rogers, S.D., Ng, K.W., and Best, J.D. 1996. Insulin receptor expression in bone. J. Bone Miner. Res. 11:1312-1320. 3. Canalis, E. 1993. Insulin like growth factors and the local regulation of
} 
bone formation. Bone. 14: 273-276.

4. Rosen, C.J., and Donahue, L.R. 1998. Insulin-like growth factors and bone, the osteoporosis connection revisited. Proc. Soc. Exp. Biol. Med. 219:1-7.

5. Buysschaert, M., et al. 1992. Proximal femur density in type I and type II diabetic patients. Diabetes. Metab. 18:32-37.

6. Piepkorn, B., et al. 1997. Bone mineral density and bone metabolism in diabetes mellitus. Horm. Metab. Res. 29:584-591.

7. Krakauer, J.C., McKenna, M.J., Rao, D.S., and Whitehouse, F.W. 1997. Bone mineral density in diabetes. Diabetes Care. 20:1339-1340.

8. Laron, Z., Klinger, B., and Silbergeld, A. 1999. Patients with Laron syndrome have osteopenia/osteoporosis. J. Bone Miner. Res. 14:156-161.

9. Kasuga, M., Karlsson, F.A., and Kahn, C.R. 1982. Insulin stimulates the phosphorylation of the 95,000-dalton subunit of its own receptor. Science. 215:185-187.

10. Ullrich, A., et al. 1986. Insulin-like growth factor-I receptor primary structure: comparison with insulin receptor suggests structural determinants that define functional specificity. EMBO J. 5:2503-2512.

11. Kadowaki, T., et al. 1996. Signal transduction mechanism of insulin and insulin-like growth factor-1. Endocr. J. 43:33-34.

12. Sun, X.J., et al. 1991. Structure of the insulin receptor substrate IRS-1 defines a unique signal transduction protein. Nature. 352:73-77.

13. Sun, X.J., et al. 1995. Role of IRS-2 in insulin and cytokine signalling. Nature. 377:173-177.

14. Tamemoto, H., et al. 1994. Insulin resistance and growth retardation in mice lacking insulin receptor substrate-1. Nature. 372:182-186.

15. Araki, E., et al. 1994. Alternative pathway of insulin signaling in mice with targeted disruption of IRS-1 gene. Nature. 372:186-190.

16. Riggs, B.L., and Melton, L.J., III. 1986. Involutional osteoporosis. N. Engl. J. Med. 314:1676-1686.

17. Trippel, S.B., Chernausek, S.D., Van Wyk, J.J., Moses, A.C., and Mankin, H.J. 1988. Demonstration of type I and type II somatomedin receptors on bovine growth plate chondrocytes. J. Orthop. Res. 6:817-826.

18. Tobe, K., et al. 1995. Identification of a $190-\mathrm{kDa}$ protein as a novel substrate for the insulin receptor kinase functionally similar to insulin receptor substrate-1. J. Biol. Chem. 270:5698-5671.

19. Yamauchi, T., et al. 1996. Insulin signalling and insulin actions in the muscles and livers of insulin-resistant, insulin receptor substrate 1-deficient mice. Mol. Cell Biol. 16:3074-3084.

20. Kaburagi, Y., et al. 1997. Role of insulin receptor substrate-1 and pp60 in the regulation of insulin-induced glucose transport and GLUT4 translocation in primary adipocytes. J. Biol. Chem. 272:25839-25844.

21. Sun, X.J., et al. 1997. The IRS- 2 gene on murine chromosome 8 encodes a unique signaling adapter for insulin and cytokine action. Mol. Endocrinol. 11:251-262.

22. Bruning, J.C., et al. 1997. Differential signaling by insulin receptor substrate 1 (IRS-1) and IRS-2 in IRS-1-deficient cells. Mol. Cell. Biol. 17:1513-1521.

23. Miyamoto, A., et al. 1998. Establishment and characterization of an immortal macrophage-like cell line inducible to differentiate to osteoclasts. Biochem. Biophys. Res. Commun. 242:703-709.

24. Yasuda, H., et al. 1998. Osteoclast differentiation factor is a ligand for osteoprotegerin/osteoclastogenesis-inhibitory factor and is identical to TRANCE/RANKL. Proc. Natl. Acad. Sci. USA. 95:3597-3602.

25. Suda, T., Nakamura, I., Jimi, E., and Takahashi, N. 1997. Regulation of osteoclast function. J. Bone Miner. Res. 12:869-879.

26. Lacey, D.L., et al. 1998. Osteoprotegerin ligand is a cytokine that regu- lates osteoclast differentiation and activation. Cell. 93:165-176

27. Canalis, E., Centrella, W., Burch, W., and McCarthy, T. 1989. Insulin-like growth factor-I mediates selective anabolic effects of parathyroid hormone in bone cultures. J. Clin. Invest. 83:60-65.

28. Pfeilschifter, J., et al. 1995. Parathyroid hormone increases the concentration of insulin-like growth factor-I and transforming growth factor beta 1 in rat bone. J. Clin. Invest. 96:767-774.

29. Hakeda, Y., et al. 1991. Prostaglandin $F_{2 \alpha}$ stimulates proliferation of clonal osteoblastic MC3T3-E1 cells by up-regulation of insulin-like growth factor I receptors. J. Biol. Chem. 266:21044-21050.

30. Rosen, C.J., et al. 1997. Circulating and skeletal insulin-like growth factor-I (IGF-I) concentrations in two inbred strains of mice with different bone mineral densities. Bone. 21:217-223.

31. Canalis, E. 1997. Insulin-like growth factors and osteoporosis. Bone. 21:215-216.

32. Reed, B.Y., et al. 1995. Serum IGF-I is low and correlated with osteoblastic surface in idiopathic osteoporosis. J. Bone Miner. Res. 10:1218-1224.

33. Hough, S., Avioli, L.V., Teitelbaum, S.L., and Fallon, M.D. 1981. Correction of abnormal bone and mineral metabolism in chronic streptozotocin-induced diabetes mellitus in the rat by insulin therapy. Endocrinology. 108:2228-2234.

34. Haffner, S.M., and Bauer, R.L. 1993. The association of obesity and glucose and insulin concentrations with bone density in premenopausal and postmenopausal women. Metabolism. 42:735-738.

35. Kao, C.H., Tsou, C.T., Chen, C.C., and Wang, S.J. 1993. Bone mineral density in patients with noninsulin-dependent diabetes mellitus by dual photon absorptiometry. Nucl. Med. Commun. 14:373-377.

36. Van Daele, P.L., et al. 1995. Bone density in non-insulin-dependent diabetes mellitus. Ann. Intern. Med. 122:409-414.

37. Porzio, O., et al. 1999. The Gly972 $\rightarrow$ Arg amino acid polymorphism in IRS1 impairs insulin secretion in pancreatic beta cells. J. Clin. Invest. 104:357-364.

38. Shao, D., and Lazar, A.M. 1999. Modulating nuclear receptor function: may the phos be with you. J. Clin. Invest. 103:1617-1618.

39. Kato, S., et al. 1995. Activation of the estrogen receptor through phosphorylation by mitogen-activated protein kinase. Science. 270:1491-1494.

40. Kato, S., Kitamoto, T., Masuhiro, Y., and Yanagisawa, J. 1998. Molecular mechanism of a cross-talk between estrogen and growth-factor signaling pathways. Oncology. 55:5-10.

41. Tremblay, A., Tremblay, G.B., Labrie, F., and Giguere, V. 1999. Ligandindependent recruitment of SRC-1 to estrogen receptor beta through phosphorylation of activation function AF-1. Mol. Cell. 3: 513-519.

42. Solomon, C., White, J.H., and Kremer, R. 1999. MAP kinase inhibits 1,25dihydroxyvitamin D3-dependent signal transduction by phosphorylation of human RXR on serine 260. J. Clin. Invest. 103:1729-1735.

43. Mochizuki, H., et al. 1992. Insulin-like growth factor-I supports formation and activation of osteoclasts. Endocrinology. 131:1075-1080.

44. Hill, P.A., Reynolds, J.J., and Meikle, M.C. 1995. Osteoblasts mediate insulin-like growth factor-I and -II stimulation of osteoclast formation and function. Endocrinology. 136:124-131.

45. Fiorelli, G., et al. 1996. Characterization and function of the receptor for IGF-I in human preosteoclastic cells. Bone. 18:269-276.

46. Hou, P., Sato, T., Hofstetter, W., and Foged, N.T. 1997. Identification and characterization of the insulin-like growth factor-I receptor in mature rabbit osteoclasts. J. Bone Miner. Res. 12:534-540.

47. Thomas, D.M., et al. 1998. Insulin receptor expression in primary and cultured osteoclast-like cells. Bone. 23:181-186. 